\title{
Identification of criteria for good logistics practices for agrobusiness development
}

\author{
Elitsa Lazarova $^{1 *}$ \\ ${ }^{1}$ D. A. Tsenov, Academy of Economics - Svishtov, Department of Strategic planning, 5250 Em. \\ Chakarov 2, Svishtov, Bulgaria
}

\begin{abstract}
The main research goal is to identify criteria for good logistics practices for the development of agribusiness in Bulgaria. The thesis is that the construction of logistics chains is a market reaction of the business for efficient use of available resources and generation of added value, contributing to cohesion between the regions in the national economy. Methods are analytical tools such as: analysis and summary of literature, tabular, graphical and schematic presentation of characteristics and trends, interview and survey on the possibilities for building logistics chains in agribusiness. The results of the study are: First. There are regional inequalities and asymmetries in territorial development. The survey data show that in less developed regions there are more logistics companies with a wide range of activities, which helps generate economic growth and achieve regional cohesion. Second. Based on the survey, the main problems and positive trends in solving internal organizational problems in business organizations are outlined. Third. The following criteria for good logistics practices in business development have been identified and substantiated: internet platform for doing business, commercial packaging and design, inventory and delivery tracking systems, shortening planning time, order processing and delivery, service and maintenance, promotional policy and establishment of logistics structures.
\end{abstract}

\section{Theoretical foundations of logistics in agriculture}

The problems related to the management and development of commodity, information and monetary processes in organizations, the formation of logistics centers and chains are the subject of numerous studies in the literature. Pioneers in the construction of modern logistics were F. Taylor (1911), H. Ford (1913) and H. Fayol (1916) with the development of the principles of organization of activity, standardization and operation of the production line and management. In 1961, Jack Burbage published the first book on inventory control. In 1997, P. Hines and N. Rich perfected the valued flow method. Under the influence of information technologies, information management programs are introduced in the organizations, initially of the production, and subsequently of the material flows. In the $80 \mathrm{~s}$ of the 20th century, the methods JIT (Just in Time), TQM (Total Quality Management), DRP (Distribution Requirements Planning) entered the business practice, which link the

* Corresponding author: e.lazarova@,uni-svishtov.bg 
production with the pre-planned opportunities and partnership with the suppliers. Michael Porter introduces the distinction between external and internal logistics and analyzes the value chain as a sequence of processes: internal logistics - production processes - external logistics - marketing and sales - customer service. Since the end of the 20th century, the concept of logistics has been expanded to include in the supply chain management not only transportation and supply, but also trade relations with contractors and service [1-2]. The specialized literature includes the concepts of "integrated logistics" [3], physical distribution and material logistics management, marketing, and business logistics. Contemporary areas are eco-logistics, environmental operations management, and information logistics [4-5]. K. Hartland considers logistics as an integration system on three levels: logistics relationships, logistics chains and business networks [6]. Since the beginning of the 21 st century, special attention has been paid to logistics partnerships [7-11] and demand models, inspections and supply models are justified. A number of authors analyze the logistics chain as a single system of interconnected subsystems. [12-14, 3].

The problems of logistics in the Bulgarian specialized literature became especially relevant after the 80 s of the 20th century, when the countries of Central and Southeastern Europe were moving towards structural social, economic, and institutional transformations [15-17]. Agriculture, as a structural sector for the national economy, is attracting research interest. The conceptual foundations of management and planning in Bulgarian agriculture are covered in the publications of M. Bogdanova, B. Borisov, M. Nikolova, M Linkova and others [18-21]. Despite the growing interest in the analysis and evaluation of logistics practices, it is necessary to conduct in-depth research and develop logistics models applicable in agribusiness, which support the efficient use of available resources and generate added value in the territories.

Agriculture creates BGN 3,698 million of GVA for Bulgaria and provides employment to 250,000 people. The total amount of realized sales of agricultural goods in 2018 amounts to BGN 6,624.2 million or $81.2 \%$ of the gross output of the Agriculture sector. Outside the industry (including exports) plant and livestock production was realized for BGN 6,235.6 million. The agricultural sector accounts for $12.4 \%$ of the total annual trade of the country, forming $15.0 \%$ of total exports and $10.1 \%$ of total imports in 2018 . There is a high growth of exports of the food industry - a total of $82 \%$, which significantly outpaces the growth of imports $-39 \%$. The positive trade balance in trade in agricultural products is an indicator of an increase in commodity in the sector, which is a result of the one-way actions of the stabilizing public measures, the regional authorities and the market orientation of the business structures in the sector.

Despite the increase in the utilized agricultural area and the consolidation of the farms in Bulgaria, the GVA created by agriculture decreased by almost $19 \%$. An alarming finding is the negative trends in the development of Bulgarian agribusiness - priority export of unprocessed agricultural products, low gross fixed capital formation in the industry, reduction of gross value added from agriculture, the presence of weak horizontal and vertical links in the food chain, weak investment and innovation activity and many more etc. The need to build logistics strategies in agricultural companies stems both from the peculiarities of production and sale of agricultural products and from strong competition in the European market. The formation of logistics chains and the closure of the value chain in the industry would generate alternative sources of income in agriculture. Opportunities for logistics chains can be sought in transport, warehousing, post-processing, sorting, cooling and freezing, construction of packaging centers and more. The EU's common European policy provides a significant financial resource for innovative entrepreneurial solutions, but the initiative remains in the hands of agricultural entrepreneurs [22].

\section{Logistics chains as a tool for territorial cohesion}


In connection with the argumentation of the thesis that logistics chains are a market reaction of business for efficient use of available resources and generating added value contributing to cohesion between regions in Bulgaria, regional inequalities are identified and the territorial location and scope of organizations in the field of logistics.

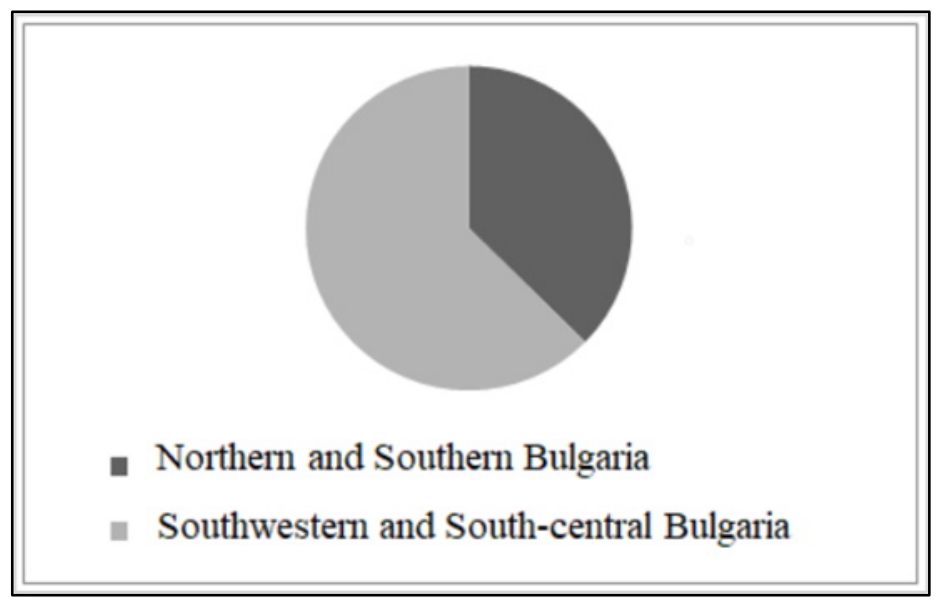

Fig. 1. Asymmetry in GVA at NUTS I level

In The common classification of territorial units for statistical purposes (NUTS) is used to identify regional inequalities [23]. At NUTS I level there is an asymmetry in the distribution of gross value added (GVA) between the two regions in the Republic of Bulgaria. (See fig. 1)

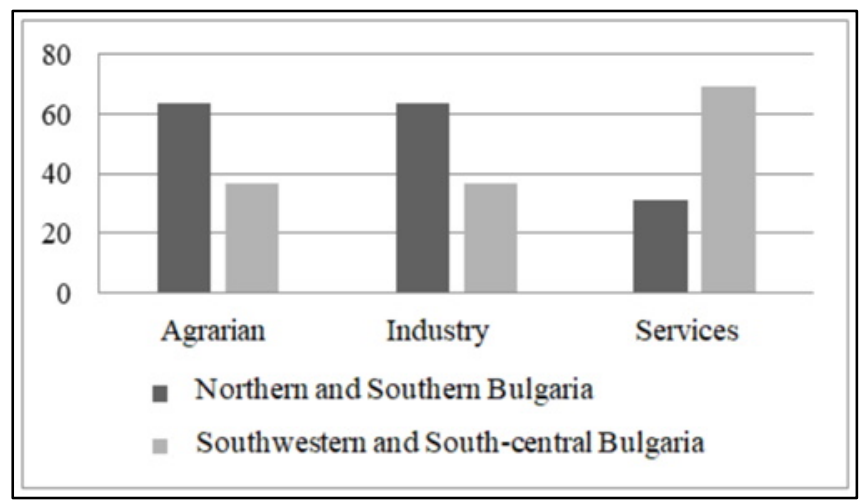

Fig. 2. Distribution of GVA by economic sectors at NUTS I level

The region Southwestern and South-central Bulgaria provides $62.6 \%$ of GVA for 2018 , and Northern and South-western Bulgaria - 37.4\%. A bipolar regional development is taking shape - a highly developing Southern region and a less developed Northern region. The distribution of GVA by economic sectors at NUTS I level for 2018 is presented in fig. 2 . Northern and South-Eastern Bulgaria is formed as a production region, providing $63.6 \%$ of the production of the agricultural sector in Bulgaria and $50.3 \%$ of the industry, as the service sector is less represented (31.2\%), while in Southwestern and South-Central Bulgaria the services sector occupies almost 70\% (68.8\%) and respectively $49.7 \%$ of industry and $36.4 \%$ of the agricultural sector. The distribution of GVA at NUTS II level is presented in fig. 3. 


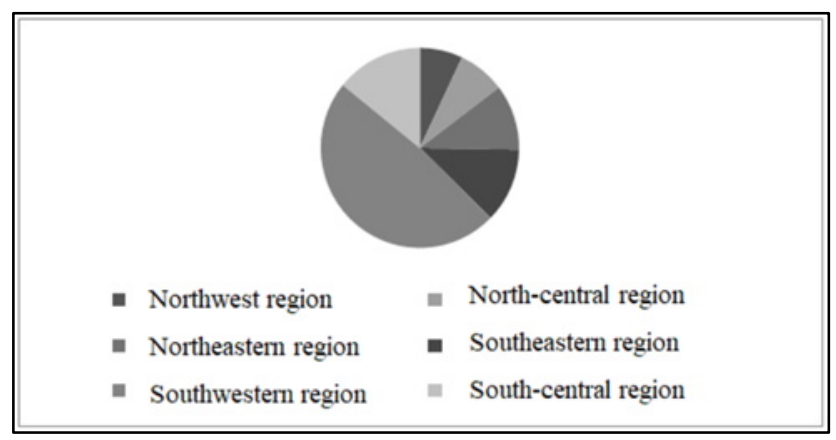

Fig. 3. Asymmetry in GVA at NUTS II level

Almost half of the GVA (48.5\%) is generated in the Southwestern region, as the other regions provide respectively: South-central region - 14.2\%, Southwestern region - $12.1 \%$, Northeast region - $10.6 \%$, North-central region - 7.7\%, North-western region - 7\%. The inequalities between Northern and Southern Bulgaria are deepening in the analysis by economic sectors (See fig. 4). The agricultural sector is most represented in the South-central region $(21.4 \%)$, in the Southwestern region $57 \%$ of the services sector and $30.4 \%$ of the industry are developed.

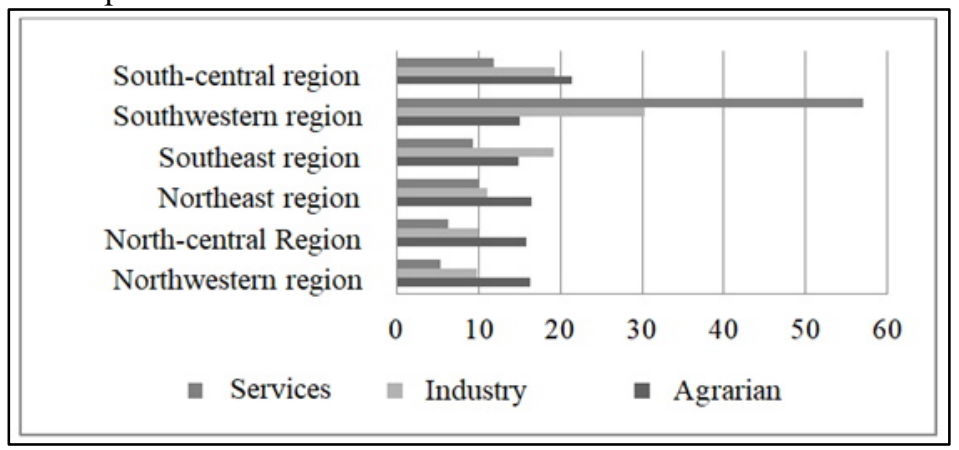

Fig. 4. Distribution of GVA by economic sectors at NUTS II level

The asymmetry in the distribution of gross value added deepens in the analysis at NUTS III level, which allows drawing a conclusion about the existence of regional inequalities and bipolar regional development of Bulgaria - a highly developing Southern region and a less developed Northern region.

The analysis of the territorial location and scope of activity of the organizations in the field of logistics is based on the studied 47 logistics companies for production and sale of agricultural products, which maintain an Internet platform in carrying out their activities. The main part of the surveyed organizations $(62.5 \%)$ operates in the Northern region, of which 20 are engaged in production activities, 5 - in processing, 3 - in trade and one in transport. In the Southern region, more than half of the surveyed logistics companies are engaged in production activities, and the rest - in trade and distribution. The territorial distribution of the surveyed logistics companies is presented in table 1 .

It is noteworthy that in the less developed Northern region there are more logistics companies with a wide range of activities, while in the more developed Southern region there are fewer organizations operating mainly in trade and distribution. This could be a result of the market orientation of business structures operating in a highly competitive environment, where the enterprising and proactive survive. 
Table 1. Distribution of logistics companies by planning regions.

\begin{tabular}{|c|c|c|c|c|c|c|c|c|c|c|}
\hline \multirow{2}{*}{$\begin{array}{c}\text { Statistical } \\
\text { region } \\
\text { (NUTS II)) }\end{array}$} & \multicolumn{2}{|c|}{ Production } & \multicolumn{2}{|c|}{ Processing } & \multicolumn{2}{|c|}{ Trade } & \multicolumn{2}{|c|}{ Transport } & \multicolumn{2}{|c|}{ Total: } \\
\hline & $\sum$ & $\%$ & $\sum$ & $\%$ & $\sum$ & $\%$ & $\sum$ & $\%$ & $\sum$ & $\%$ \\
\hline $\begin{array}{c}\text { Northwestern } \\
\text { Region }\end{array}$ & 5 & 15,6 & $\mathrm{x}$ & $\mathrm{x}$ & $\mathrm{x}$ & $\mathrm{x}$ & $\mathrm{x}$ & $\mathrm{x}$ & 5 & 11 \\
\hline $\begin{array}{l}\text { North-central } \\
\text { Region }\end{array}$ & 7 & 21,9 & 2 & 40 & 1 & 11,1 & 1 & $\mathrm{x}$ & 11 & 23 \\
\hline Northeast region & 3 & 9,38 & 3 & 60 & $\mathrm{x}$ & $\mathrm{x}$ & $\mathrm{x}$ & $\mathrm{x}$ & 6 & 13 \\
\hline Southeast region & 5 & 15,6 & $\mathrm{x}$ & $\mathrm{x}$ & 2 & 22,2 & $\mathrm{x}$ & $\mathrm{x}$ & 7 & 15 \\
\hline $\begin{array}{c}\text { Northern } \\
\text { Region } \\
\text { (NUTS I) } \\
\end{array}$ & 20 & 62,5 & 5 & 100 & 3 & 33,3 & 1 & $\mathbf{x}$ & 29 & 62 \\
\hline $\begin{array}{l}\text { Southwestern } \\
\text { region }\end{array}$ & 8 & 25 & $\mathrm{x}$ & $\mathrm{x}$ & 5 & 55,6 & $\mathrm{x}$ & $\mathrm{x}$ & 13 & 27 \\
\hline $\begin{array}{c}\text { South-central } \\
\text { region }\end{array}$ & 4 & 12,5 & $\mathrm{x}$ & $\mathrm{x}$ & 1 & 11,1 & $\mathrm{x}$ & $\mathrm{x}$ & 5 & 11 \\
\hline $\begin{array}{c}\text { Southern } \\
\text { Region } \\
\text { (NUTS I) }\end{array}$ & 12 & 37,5 & $\mathbf{x}$ & $\mathbf{x}$ & 6 & 66,7 & $\mathbf{x}$ & $\mathbf{x}$ & 18 & 38 \\
\hline $\begin{array}{l}\text { Total surveyed } \\
\text { organizations: }\end{array}$ & 32 & 100 & 5 & 100 & 9 & 100 & 1 & $\mathbf{x}$ & 47 & 100 \\
\hline
\end{tabular}

Based on the above, the following summaries and conclusions can be synthesized:

- there are regional inequalities and bipolar territorial development in Bulgaria - a highly developed Southern region and a less developed Northern region;

- Logistics chains help generate economic growth and achieve regional cohesion.

\section{Identification of good logistics practices}

To identify good logistics practices, data from a survey of 212 business organizations by planning regions were used - 183 micro-enterprises, 23 small, 2 medium and 1 large. (See Fig. 5)

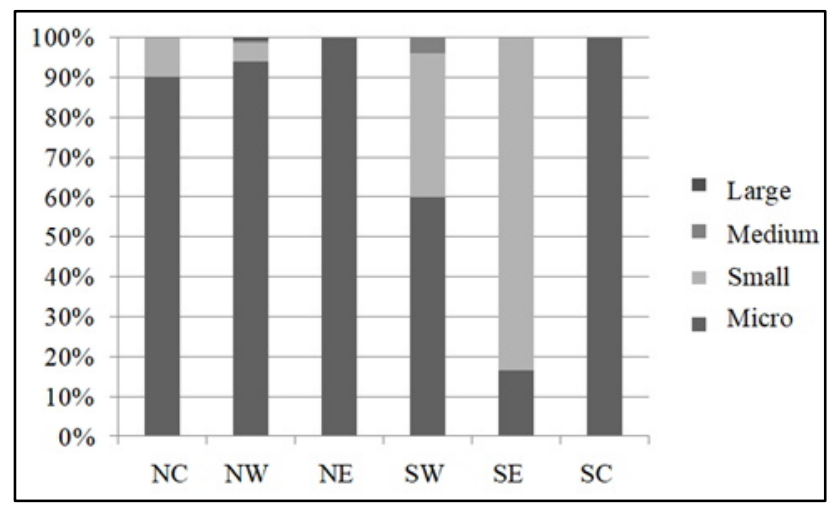


Fig. 5. Distribution of respondents by planning regions ${ }^{\dagger}$

The majority of respondents are engaged in trade (72\%), 14\% - services and $11 \%$ production. Most of the respondents define the business as successful (35\%) or satisfactory $(38 \%), 25 \%$ - as variable and only 5 organizations (2\%) assess it as unsuccessful. The optimistic expectations of the business $(60 \%)$ in connection with the pandemic from COVID 19 are impressive, as one fifth indicate that the epidemic situation requires changes in the organization of work processes and only 6 of the respondents have pessimistic expectations. According to the respondents, the prospects for business organizations are mainly towards preservation (47\%) and expansion (45\%) and only 10 organizations envisage restructuring and 7 - shrinking. The competitive profile of the surveyed organizations reflects the intensifying competitive environment for business in the country - 74\% of respondents have more than 5 competitors, $11 \%-3-4$ and only $10 \%$ have $1-2$. This requires an orientation towards innovations, which is confirmed by the data in the survey - there is no organization without at least one of total of 293 innovations. The directions of the implemented innovations in the surveyed organizations are presented in figure no. 6 . The main innovations (229) are related to equipment, 36 - to process, 24 - to buildings and only 3 are focused on products, which could be an indicator of market behavior in business organizations.

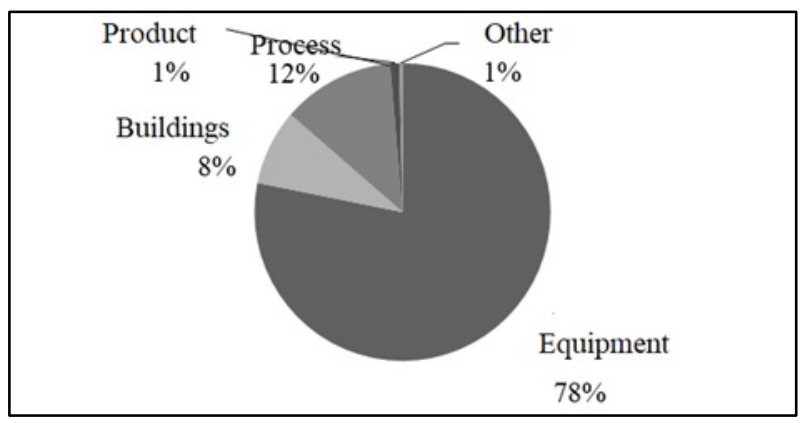

Fig. 6. Directions for renewal in business organizations

The analysis of the survey data on the number of suppliers and customers are also indicative of the formed market behavior in the respondents and work with an average of four suppliers and 94 customers. (See Fig. 7)

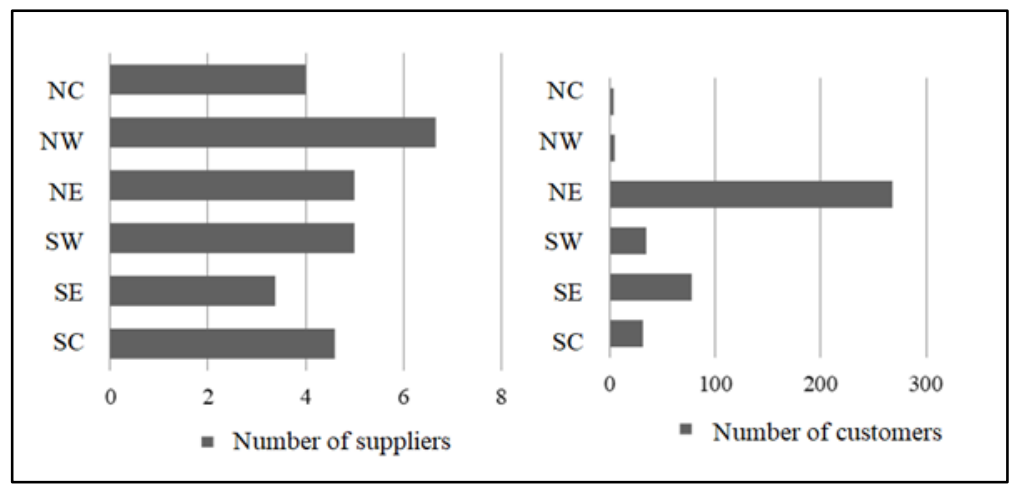

Fig. 7. Average number of suppliers and number of customers of the respondents ${ }^{\dagger} \mathrm{NC}$ - North-central region, NW -Northwest region, NE - Northwest region, SW-Southwest region,
$\mathrm{SE}$ - Southwest region, SC - South-central region. 
The main problems for business development can be systematized into two groups internal and external. The main problems of organizations with the external environment are related to unfair competition, limited markets, customers and suppliers, bureaucratic and administrative restrictions. One-fifth of the surveyed organizations indicate that they are subject to strong and $13 \%$ to medium unfair competition. On a positive note, $67 \%$ of respondents experience weak unfair competition. The restriction of unfair competition, as well as the fact that the shortage of markets for $70 \%$ of the respondents is of low importance (See Figure no. 8) are indicators for improvement and stability of the business environment in the country. Only $2 \%$ of respondents point to the limited product market as a serious problem, and the remaining $28 \%$ define it as medium.

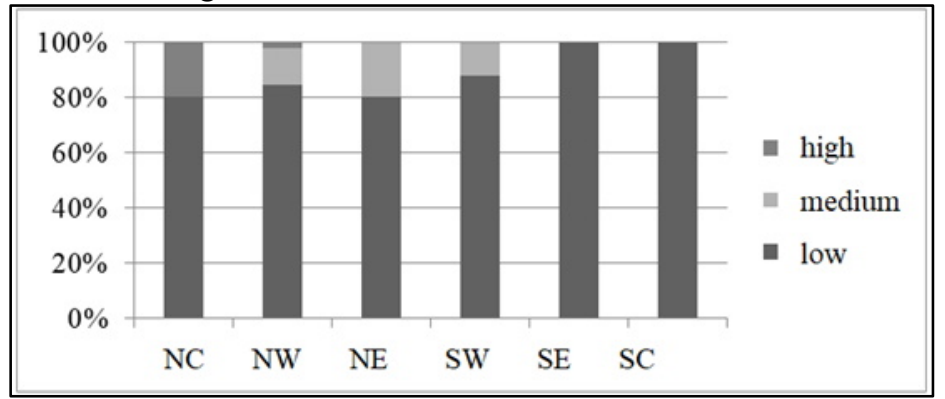

Fig. 8. Degree of limitation in the markets of business organizations

The main problems for half of the surveyed organizations are related to the customers and suppliers. More than half of the respondents define as low (47\%) and medium (14\%) the degree of significance of the problem of insolvency and customer claims, and for $39 \%$ it is high. Problems with incorrect suppliers are high for $46 \%$ of respondents, $8 \%$ define them as medium and 46\% - weak. (See Fig. 9) More than half of the respondents (52\%) rate their institutional burden as strong (bureaucracy and problems with the institutions - HEI, NRA, Traffic Police, etc.), the average rate is according to $9 \%$, and the rest indicate that although weak, they are also burdened with institutional problems.

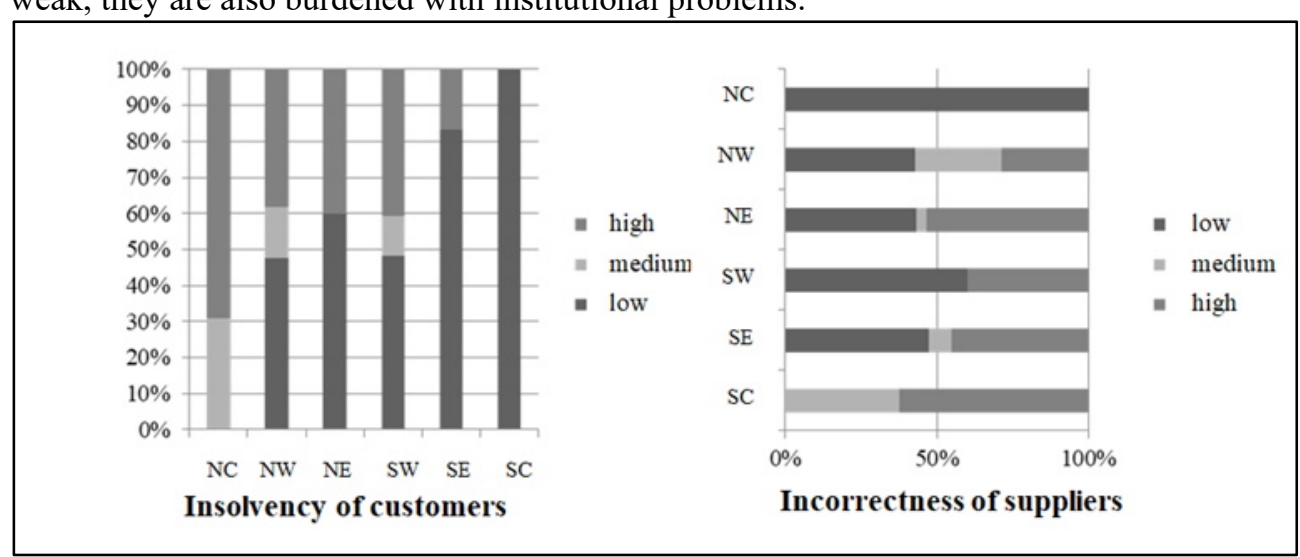

Fig. 9. Incorrect customers and suppliers in business organizations by planning regions

Internal organizational problems are most often related to: insufficient funds, high operating costs, low profits, high risk and losses, depreciated production base and technology, lack of qualified personnel, irrational use of available resources.

The majority of respondents $(71 \%)$ indicated a low level of cash shortages, but the rest experienced difficulties - $26 \%$ on average and 3\% - high. Only $8 \%$ of the respondents declare that the costs for the activity are high, for $48 \%$ the costs are small, and for $44 \%$ - medium. 
The level of profit from the activity is high, according to a quarter of the respondents, it is low for $66 \%$ and on average for $10 \%$ of the respondents. $7 \%$ experience high risk and losses, $35 \%$ indicate an average level and the main part of the respondents $(58 \%)$ determine a low level of risk. Almost half of the respondents have problems with the depreciated production base and technologies, but it is a positive fact that $44 \%$ focus on building a new one and $11 \%$ - on renovating the existing one. Most business organizations (70\%) do not feel a lack of qualified staff, but of the remaining $28 \%$ indicate a medium and $2 \%$ - a high need for specialists. The tendency towards optimal use of available resources is intensifying in $42 \%$ of the surveyed business organizations, and $48 \%$ define it as irrational.

The data from the survey show a positive trend in solving internal organizational problems in business organizations, compared to similar studies in the period 2008-2015 [22, 24-25]. There are less and less business structures that experience problems with cash management, operating costs and profits. This is indicative of the formed market behavior and management and organizational skills of the company management. The problems related to the optimal utilization of the available resources, the relations with the external environment and the personnel are brought to the fore.

In connection with the selection of criteria for good logistics practices, the respondents were asked questions related to the identification of their advantages over competitors and the advantages of competitors, as well as the applied good practices in the organization. The main advantages of the competitors, ranked according to the choice of the respondents, are related to the prices $(17 \%$ of the answers), the introduced modern technologies $(16 \%)$, own fleet $(16 \%)$, warehouse $(13 \%)$, speed of service $(10 \%)$, qualified staff $(10 \%)$, quality $(7 \%)$, low production costs $(4 \%)$, low resource prices $(3 \%)$, closed cycle $(2 \%)$ Respondents indicate (more than 1 answer) the following advantages over its competitors: low prices (31\%), fast service $(29 \%)$, quality and low price $(12 \%)$, warehouse $(11 \%)$, fleet $(11 \%)$, high price quality (4\%), high performance technologies $(2 \%)$.

More than half of the respondents indicated that they use an Internet platform to do business, but $47 \%$ have not yet focused on digitalization. The importance of commercial packaging and design in sales is high for $51 \%$ of respondents, average for $6 \%$ and weak for $43 \%$ of them. The promotional policy of business organizations includes: bonus on reordering (48\%), Service and support $(19 \%)$, Discounts on the price when buying large quantities (4\%), as $14 \%$ of respondents state that they do not do so. Good practice is the use of GPS tracking and delivery tracking systems (52\%), notification upon receipt (45\%) and specialized software for complete tracking of stocks and deliveries (3\%).

In the surveyed organizations the time for delivery and processing of requests varies from $1-3$ working days (45\%) to a week, as the planning of requests for incoming resources is rhythmic in $51 \%$ of respondents, and in $49 \%$ of them - when reaching a certain minimum.

In almost all surveyed organizations (91\%) there are separate logistics structures - a warehouse for finished products $(33 \%)$ and for raw materials $(29 \%)$, a packaging center (14\%), and $24 \%$ have a separate logistics department.

Based on the study, the following good logistics practices have been identified:

- internet platform for doing business;

- commercial packaging and design (strong importance 51\%, weak 43\%);

- inventory and delivery tracking systems;

- shortening the time for planning, processing orders and delivery;

- service and maintenance;

- promotional policy;

- separate logistics structures.

\section{Conclusions}


On the basis of the conducted research the following summaries and conclusions can be made. First. There are regional inequalities and bipolar territorial development in Bulgaria a highly developed southern region and a less developed northern region. The data from the survey show that logistics chains help generate economic growth in less developed areas and achieve regional cohesion. Second. Based on the data from the survey, the main problems for business development have been identified. There is a positive trend in solving internal organizational problems in business organizations, bringing to the fore the problems related to the optimal use of available resources, relationships with the external environment and staff, which is an indicator of market behavior and management and organizational skills of company management and improving the business environment in the country. Third. Based on the survey, the following criteria for good logistics practices in business development have been identified and substantiated: internet platform for doing business, commercial packaging and design, inventory and delivery tracking systems, shortening planning time, order processing and delivery, service and maintenance, promotional policy and establishment of logistics structures.

\section{References}

1. J. B. Blaser, The Supply Chain Revolution, The Performance Advantage (5/1995)

2. L. Chankova, Economic thoughts J., 1, 16-34 (2005)

3. I. Iliev, V. Dimitrova, Logistics in corporate practice, (Varna: Slavena, 2006)

4. L. S. Koh, C. Birkin, L. Lewis, A. Cashman, Current issues of sustainable development in the global market: perspectives from sustainable production, eco-supply chain and eco-logistics, International Workshop on Supply Chain Management and information Systems, Thessaloniki, Greece (2005)

5. P. R. Kleindorfer, Environmental Management and Operations Management, Risk Management Review, (Spring, 2001)

6. C. Harland, Br. J. Manag., 8 (1996)

7. J. C. Andraski, Food logistics Website, Preluat de pe, (1999) http://www.foodlogistics.com/collaboration.html.

8. M., Citera, M. D. McNeese, C. E. Brown, JASIST, 46(7), 551-559 (1995)

9. S. H. Haeckel, J. Interact. Mark., 12(1), 63-71 (1998)

10. V. Sriam, R. Krapfel, R. Spekman, J. Bus. Res., 25(4), 303-320 (1992)

11. J. T. Mentzer, J. T. Foggin, S. G. Golicic, Supply Chain Manag. Rev., 4, 11-23 (2000)

12. R. Monezka, R. H. Trent, Purchasing and Supply Chain Management, (South-Western College Publishing, ITP Company, 1998)

13. K. Lumsden, L. Hulten, J. Waidringer, Outline for a conceptual framework on complexity in Logistic Systems, Working Paper TFK\&CECIL, (Sweden, 1998)

14. K. Vatasek, Supply Chain and Logistics terms and glossary, Supply Chain Visions, (Washington, CSCMP, 2005)

15. N. Mitev, M. Chipriyanov, Marketing and logistics, (Svishtov: AI Tsenov, 2001)

16. M. Chipriyanov, N. Mitev, Logistics - theory and practice, (Veliko Turnovo: Abagar, 2005)

17. Y. Koraliev, Supply chain management, (Sofia: UI "Economy", 2013) 
18. B. Borisov, M. Bogdanova, E. Lazarova, E. Prashekvova, Y. Gospodinov, M. Soyanova, Methodological and organizational aspects of planning in Bulgaria (problems and solutions), (Svishtov: AI Tsenov, 2015)

19. K. Slaveva, P. Petkov, Statistical analysis of socio-economic and demographic differences and inequalities between regions in Bulgaria, in The Research Almanach, D. A. Tsenov Academy of Economics -Svishtov, 21, 384-413 (2014)

20. M. Nikolva, M. Linkova, Paradigms of knowledge, Praha, 4, 68-81 (2018)

21. M. Linkova, Investment planning and the chaos in the economy the chaos and challenges of planning, (Svshtov: AI Tsenov, 1995)

22. M. Linkova, M. Nikolova, E. Lazarova, Opportunities for building applied innovation strategies in Bulgarian agricultural companies, in Research Almanac "Economics and Management on the Road to Sustainable Development", 23, 358-386 (2016)

23. Classification of Territorial Units for Statistics in Bulgaria (NUTS), https://www.nsi.bg/bg/content/157/basic-page/

24. M. Nikolova, M. Linkova, E. Lazarova, Opportunities for forming an agritourism product in Bulgaria, in Almanac for Scientific Research, D. A. Tsenov Academy of Economics, Svishtov, 11, 287-324 (2010)

25. M. Linkova, Parameters of the localization choice for investments in agricultural companies, in Library "Education and Science", AP "Tsenov" - Svishtov, 19 (2012) 